VET BRIEF

ZOOS' PRINT JOURNAL 20(5): 1877

\section{CLINICO-HAEMATOLOGICAL STUDY IN AILING PIGEONS OF NAGPUR CITY}

\section{C.G. Panchabhai, A.M. Rode, D.B. Sarode, A.G. Bhandarkar, N.P. Dakshinkar and G.R. Bhojne}

\author{
Nagpur Veterinary College, Nagpur, Maharashtra 440006, India
}

In recent years a number of deaths of pigeons have been reported from different parts of the country, however causes have remained unknown. The present clinico-haematological investigation is an important criterion to derive data that can be used for disease control and reduce mortality in pigeons.

Methods: The present study was undertaken during the year 2002 on the domestic pigeons Columbia livia reared in different parts of Nagpur city and data on area, number of birds infected, clinical symptoms, nature of infection, morbidity percentage were collected. The ailing birds were kept under observation and subjected to detail clinical investigation. Blood samples were collected from the wing vein. Blood smears and serum samples were collected and $\mathrm{Hb} \%, \mathrm{PCV}, \mathrm{DLC}$ and TLC estimations were carried out.

Results: A total of 1,166 pigeons were studied from different parts of the city, out of which 840 were found exhibiting signs of torticollis prominently accompanied with circling movement, drooping feathers, greenish watery diarrhoea and inability to peck grains. Some pigeons were exhibiting nervous signs like head shaking, muscular tremors, aiding movements, disorientation, incoordination and drooping of wings. In a few pigeons sneezing, nasal discharge and dullness were also observed. These observations corroborate with that reported by Barton et al. (1992) and Pennycott (1994).

The morbidity and mortality rates were found to be 70.04 and 48.71 percent, respectively, though not statistically significant as far as total number of pigeons was concerned. These findings are supported by that of Afaleq et al. (1993), who reported that variation in morbidity and mortality rates might be due to the variable immune response of the pigeons from different flocks.

The area-wise percentage of morbidity and mortality in pigeons during this study were also found to be varying. The highest percentage of mortality $(60 \%)$ was found at Somwari quarters followed by Nandanvan (58\%) and Khamla (57.14\%). History revealed that none of the owners had prophylactically vaccinated their flock against any disease. The highest mortality rate can be attributed to this failure. The affected pigeons were not segregated, and therefore remained as a source of infection for the whole flock.

It appears from the observations that immunization, environmental and housing conditions are crucial factors for the maintenance of disease free pigeon population.
Haematological study in respect of haemoglobin, total erythrocyte count, total leucocyte count, packed cell volume and differential leucocyte count was conducted in all the ailing pigeons as well as in a group of normal healthy pigeons (Table 1). The overall haemoglobin in ailing pigeons was observed to be reduced significantly than that of normal pigeons. Inability to peck grains and drink water by the pigeons was due to torticollis that led to starvation. This might be a major factor for the significant reduction of the haemoglobin and increase in PCV of affected pigeons.

The reduction in total erythrocyte count might be the sequel of virulence of the infectious agent and resultant starvation. On differential leucocytes count the increase in neutrophil \% in the ailing pigeons observed is reported to indicate prevalence of some infection (Verma, 1976). Similarly the increase in eosinophil $\%$ can also be attributed to the presence of parasitic infection. The average lymphocyte percentage in the ailing pigeons showed non significant increase, which might have been due to the difference in the severity of the infection among the pigeon populations.

The overall break-up of the helminth infection observed can be given as Capillaria columbae (46.42\%), Ascardia columbae (30.35\%), Syngamus trachea (12.5\%), Raillietina cesticillus (10.71\%) and Heterakis gallinarum (8.92\%). Similar parasitological findings were recorded by Mushi (1988) and Kurkure et al. (1998).

Table 1. Haemotological profile of infected and non-infected pigeons from different parts of Nagpur city

\begin{tabular}{lll}
\hline Haematological profile & Infected pigeons & Normal pigeons \\
\hline Packed Cell Volume (\%) & $46.0 \pm 1.10$ & $39.66 \pm 4.48$ \\
Haemoglobin (gm \%) & $14.16 \pm 0.37$ & $17.03 \pm 0.48$ \\
Total Erythrocyte count $\times 10^{6} / \mathrm{mm}^{3}$ & $2.75 \pm 0.18$ & $3.06 \pm 0.11$ \\
Total Leukocyte count $\times 10^{3} / \mathrm{mm}^{3}$ & $19.32 \pm 0.77$ & $16.16 \pm 1.66$ \\
Differential leukocyte Count & & \\
a) Neuterophil \% & $28.6 \pm 4.27$ & $25.33 \pm 0.66$ \\
b) Lymphocyte \% & $71.57 \pm 1.21$ & $67.66 \pm 0.71$ \\
c) Monocyte \% & $2.75 \pm 0.75$ & $3.16 \pm 0.4$ \\
d) Eosinophil \% & $5.14 \pm 0.76$ & $2.5 \pm 0.22$ \\
e) Basophil \% & $1.4 \pm 0.2$ & $1.6 \pm 0.44$ \\
\hline
\end{tabular}

\section{REFERENCES}

Afaleq, A.I., E.M.E. Abu Elzein, A.A. Gameel, M. Awaad, M.M. Hassanein, A.I.A. Afale and E.M.E.A. Elzein (1993). A severe nervous disease in fancy pigeons caused by paramyxovirus-I in Saudu Arabia. Revue-d Elevage-et-de-medicine-veterinary-despays-Tropicaux 46(4): 545-547.

Barton J.T., A.A. Bigaford, G.L. Looper, B.R. Charlton and C.J. Cardona (1992). Avian paramyxovirus type-I infections in racing pigeons in California: I clinical signs, pathology and serology. Avian Disease 36(2): 463-468.

Kurkure N.V., S.W. Kolte, A.G. Ganorkar \& A.G. Bhandarkar (1998). Raillietina cesticillus in pigeons (Columbia livia). Indian Veterinary Journal 75: 835-836.

Pennycott, T.W. (1994). Avian paramyxovirus type-I in feral pigeons Veterinary Records 134(21): 560.

Verma, M.P. (1976). Drug and Animal Diseases. $1^{\text {st }}$ edition. K.A.S. Publisher and Distributors, Vallabhnagar, India.

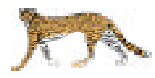

